\title{
A Study on the Phosphorus Removal Using HFO Coated Media from Wastewater Treatment Plant Effluent
}

\author{
Eun-young Jo, Younghee Kim, and Chan-gyu Park
}

\begin{abstract}
The removal of phosphorus by adsorption is investigated in this study. Adsorption is one of efficient method to remove phosphorus in wastewater. Media such as zeolite, activated carbon, and quartz sand was coated with hydrated ferric oxide, and the adsorption efficiency of phosphorus is increased. In this study, three kinds of media (zeolite, activated carbon, and quarts sands) is coated with hydrated ferric oxides(HFO) and the removal efficiency of phosphorus was investigated.
\end{abstract}

Index Terms-Phosphorus, phosphorus removal, hydrated ferric oxide, adsorption, wastewater.

\section{INTRODUCTION}

Phosphorus is an essential element for life; it is a macronutrient constituent of most biological tissues and hence is a vital commodity for sustaining food production. Phosphorus resources are finite, with estimates suggesting they could be limited to a few decades. Whilst more recent surveys have extended the timeline of this prediction, phosphorus is ultimately limited and issues surrounding food security necessitate the consideration of its recovery from wastewater streams. For instance, in the UK, wastewater contains sufficient phosphate to meet around $50 \%$ of the country' s fertilizer demand. On the other hand, the considerable volume of wastewater that contains phosphate deteriorates natural aquatic environments and water quality and is the main cause of eutrophication in rivers and lakes. This problem has increased concerns regarding water quality and as a consequence, new legislation has come into force to regulate the release of phosphate to natural systems. The United States Environmental Protection Agency (USEPA) has recommended that the maximum level of phosphorus in water should not exceed $50 \mu \mathrm{g} / \mathrm{L}$, and the Florida Everglades Forever Act has also recommended a new mandate of $10 \mu \mathrm{g} / \mathrm{L}$ of phosphorus in water. Equivalent requirements exist in the EU where the Water Framework Directive is likely to Phosphorous is one of the limiting nutrients for the growth of phytoplankton and algae and is therefore one of leading causes of eutrophication. The presence of dissolved phosphate in surface waters has become a worldwide

Manuscript received December 5, 2016; revised May 1, 2017.

Eun-young Jo is with Korea Testing Laboratory, Korea (e-mail: eyjo@ktl.re.kr).

Younghee Kim is with ILSHIN Environmental Engineering Co. Ltd and Hoseo University, Korea (e-mail: younghee.km@gmail.com).

Chan-gyu Park is with Korea Testing Laboratory, Korea (e-mail: pcg6189@naver.com). environmental issue because of its marked negative impacts to water quality that cause eutrophication problems [1]. Enhanced removal of phosphate from waste effluents is thus of considerable significance before their discharge into the environment. Various techniques have been used for phosphate removal, including chemical precipitation, biological treatment, ion exchange and adsorption, etc. Among them, adsorption is one of the most attractive approaches with the advantage of operation simplicity, low operation cost and having effective removal without yielding harmful by-products. Many types of adsorbents for phosphate removal have been investigated, which include aluminum and aluminum(hydr) oxide, poly-meric ligand exchanger, iron oxides, dolomite, red mud, zeolite, furnace slag, mesoporous silicates and so on. However, most of these adsorbents would be very difficult to be reused since they are in powder and will sink down to the bottom of the water bodies which may cause environmental secondary pollution. To further improve the recyclability and adsorption efficiency, it is necessary to develop some novel phosphate-specific adsorbents which would be easily available for the water bodies. In our previous study, lanthanum(hydr) oxide-doped activated carbon fiber (ACF-La) has been prepared for phosphate removal. Lanthanum(hydr) oxides are the active component by its high phosphate adsorption capability, and suitable lanthanum may be nontoxic and environment-friendly, whereas activated carbon fiber (ACF) provides a uniform pore distribution, large surface areas for active metal oxides so that the lanthanum could be locked into its structure for reducing the release of lanthanum to water bodies. Unlike other activated carbon material, the fibers had smaller diameters, which make that the particles more uniformly distributing throughout the media. This property would be favorable for overcoming the diffusion resistance of phosphate in congregated metal oxides particles. The new hybrid adsorbents would have more widespread feasibility and applicability on phosphate adsorption in a column for a continuous flow system and on leaching at a commercial scale. But the high price and scarcity of the lanthanum resources hinder its practical application. In the past decades ferric (hydr)oxides (low-cost, resource-rich) have proved to exhibit specific removal of anionic pollutants, such as phosphate, arsenite/arsenate, or selenite, from contaminated waters. Was also developed hydrated ferric oxide doped ACF (ACF-HFO) for phosphate removal, with the maximum adsorption capacity of $12.86 \mathrm{mg} / \mathrm{g}$, in our previous study. In order to obtain a cost-effective adsorbent, the authors incorporated ferric into lanthanum doped ACF (ACF-LaFe). It is expected to achieve the dual aims of ideal phosphate removal capacity and low running cost. As ferric hydroxide and lanthanum hydroxide have different solubility 
product, the metal (hydr)oxide particles would generate and sink under different $\mathrm{pH}$ values. So it is not suitable to use the traditional method for system of ACF-LaFe by dipping ACF into the mixed metal hydroxide solution. A modified form of a proprietary synthetic process developed by SolmeteX, with the advantage of easy to operate operation, simple process and error control of loading a variety of metals at the same time, was used in this study. The ultrasonic radiation was adopted for enhancing mass transfer process. Human activities have altered the phosphorus global cycle consuming in days or years what in the nature takes millions of years to be created [1]. Phosphorous is an essential element of life and of the modern agricultural system [2], and it is a very valued resource due to its main role in fertilizer production as well as in sustainable food production. Fertilizers are produced from phosphate rock and whereas the supply of phosphate rock is limited at the global scale, the fertilizer consumption is in continuous growing [3], [4]. Further- more, phosphorous is one of the limiting nutrients for the growth of phytoplankton and algae and is therefore one of leading causes of eutrophication. The discharge of wastes containing phosphorus must meet new environmental quality standards for this element. Different technologies have been applied for phosphate removal from wastewater namely physical, chemical precipitation by using ferric, calcium or aluminium salts [5], biological [6], and adsorption [7], [8]. However, physical processes are expensive and inefficient and chemical precipitation and biological processes have been widely used but they suffered from high costs, sludge handling and operational difficulties to achieve the low phosphate levels required [9]-[11]. For example, the phosphorus concentration in dischargedwater to natural waterbodies has been limited to $10 \mathrm{mg} \mathrm{P} / \mathrm{L}$ in United States of America, $100 \mathrm{mg}$ P/L in South Korea or $400 \mathrm{mg} \mathrm{P} / \mathrm{L}$ in Europe. In view need to reduce of the discharge limits, research is oriented to tertiary treatments for phosphorus removal since conventional chemical and biological nutrient removal cannot reach values below 500 $\mathrm{mg} \mathrm{P} / \mathrm{L}$. Adsorption is the most suitable technique for phosphate removal, particularly for low phosphate concentrations. Several types of phosphate adsorbents have been investigated such as aluminium/ ferric oxide or hydroxide, inorganic sorbents, polymeric anion exchange resins, fly ash and activated carbon, and magnetic chitosan composites. Different technologies have been applied for phosphate removal from wastewater namely physical [1], chemical precipitation by using ferric, calcium or aluminum salts [2], biological [3], and adsorption [4], [5]. Chemical treatment for phosphorus removal involves the addition of metal salts to react with soluble phosphate to form solid precipitates that are removed by solids separation processes including clarification and filtration. The most common metal salts used are in the form of alum (aluminum sulfate), sodium aluminate, ferric chloride, ferric sulfate, ferrous sulfate, and ferrous chloride.

In this study, three kinds of media (zeolite, activated carbon, and quarts sands) is coated with hydrated ferric oxides (HFO). To investigate the removal efficiency of phosphorus, phosphorus adsorption ability of each coated media was tested with artificial wastewater.

\section{MATERIALS AND METHODS}

\section{A. Experimental Method}

The zeolite, activated carbon, and quartz sand is used as media in this study. The media was homogenized with $\Phi 2 \mathrm{~mm}$ sieve. The media were coated with $7 \mathrm{mg} / \mathrm{L}$ of HFO solution. To investigate the effect of $\mathrm{pH}$ on the coating, the coating was conducted under $\mathrm{pH} \mathrm{4,} \mathrm{7,} 10$ (Fig. 1).

To evaluate the phosphate removal efficiency of coated media, the artificial wastewater was used in this study. The media were soaked in the $5 \mathrm{mg} / \mathrm{L}$ of $\mathrm{H}_{3} \mathrm{PO}_{4}$ solution during 1 hour with shaking. Sampling was conducted after 10, 30, 60 min of treatment (Fig. 1).

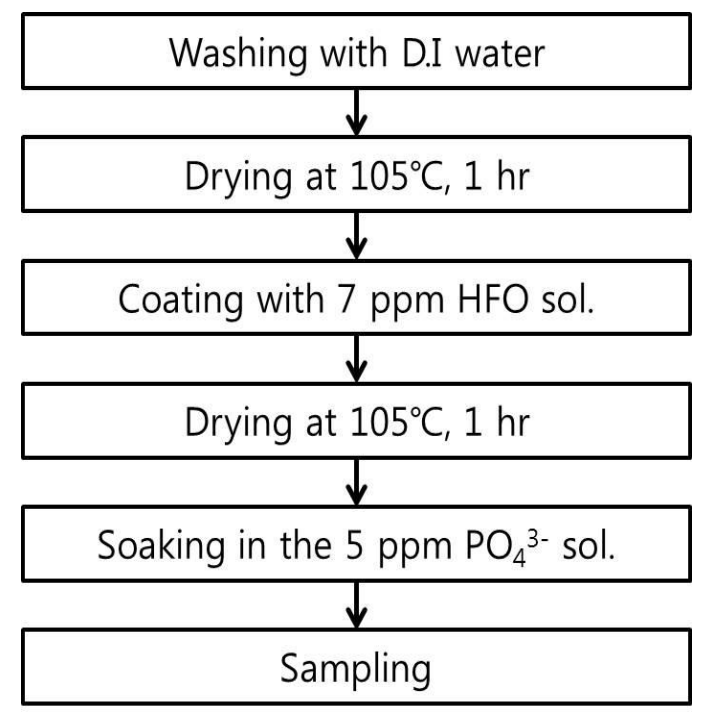

Fig. 1. Experimental steps in this study.

\section{B. Analytical Methods}

To evaluate the phosphorus removal effect of HFO coated media, the artificial wastewater was used to investigate removal efficiency of phosphate. The phosphate concentration was analyzed by Hach method 8048(ascorbic acid method). BET surface area was analyzed with ASAPTM 2020 BET analyzer (Micromeritics). The surface analysis was conducted with the FE-SEM(Hitachi).

\section{RESULT AND DISCUSSION}

The physical properties of silica, zeolite, and activated carbon were analyzed in this study (Table 1). Relative density of silica, zeolite, activated carbon was $151.48,90.57$, and $52.24 \mathrm{~g} / \mathrm{cm}^{3}$, respectively. The BET surface area were 1.75 $\mathrm{m}^{3} / \mathrm{g}$ for silica, $16.19 \mathrm{~m}^{3} / \mathrm{g}$ for zeolite, $821.38 \mathrm{~m}^{3} / \mathrm{g}$ for activated carbon. It can be supposed to activated carbon has highest internal micro pore area.

TABLE I: THE PHYSICAL PROPERTIES OF MEDIA

\begin{tabular}{lccc}
\hline \hline & Silica & Zeolite & $\begin{array}{c}\text { Activated } \\
\text { Carbon }\end{array}$ \\
\hline Relative density $\left(\mathrm{g} / \mathrm{cm}^{3}\right)$ & 151.48 & 90.57 & 52.24 \\
BET surface area $\left(\mathrm{m}^{3} / \mathrm{g}\right)$ & 1.75 & 16.19 & 821.38 \\
\hline \hline
\end{tabular}


The SEM analysis was conducted to examine the HFO coated surface of each media. Fig. 2 shows the quarts sand media coated by HFO, the HFOs were coated on the surface of quarts sand.
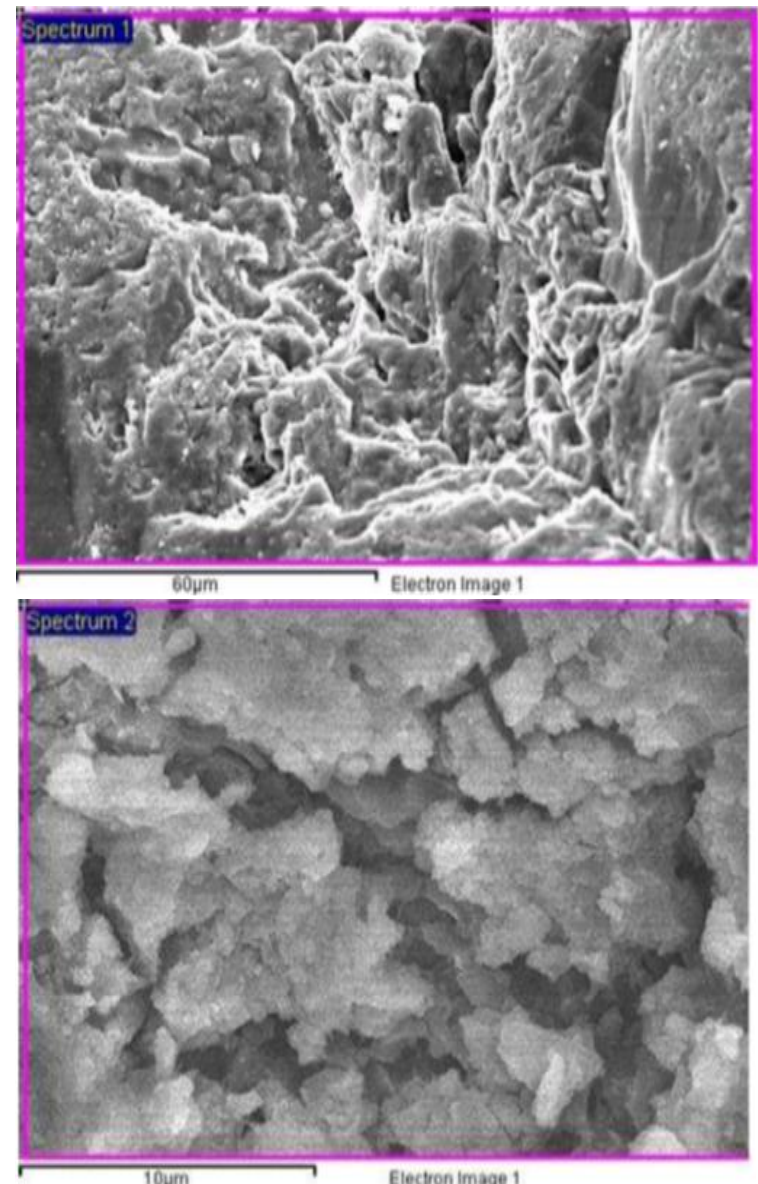

Fig. 2. The SEM photo of quarts sand media before and after the HFO coating.

The removal efficiency of phosphate was evaluated after 20 min of treatment with HFO coated media (Fig. 3). The silica and zeolite shows above $80 \%$ of removal efficiency in every $\mathrm{pH}$ conditions. For the silica, removal efficiency of phosphate under $\mathrm{pH} 4$ is slightly lower than $\mathrm{pH} 7,10$. This is because the zeta-potential of silica varies according to the $\mathrm{pH}$. The PZNPC (Point of zero net proton charge) of silica is 2 . It means the zeta-potential of silica is negative charge in the conditions of above $\mathrm{pH} 2$. The zeolite shows very low differences as the $\mathrm{pH}$, because it has negative charge in every $\mathrm{pH}$ condition. In the study of Kędziora et al(2014), the zeta-potential of zeolite get gradually more negative with the increase in $\mathrm{pH}$ [6]. In case of activated carbon, the removal efficiency of phosphate got lower as the $\mathrm{pH}$ increased. Under $\mathrm{pH} 10$, only about $50 \%$ of phosphate was removed.

The ferric oxide coated on the surface of media is reacting with phosphate in wastewater as eq. 1 3. The coating efficiency is determined by zeta potential of each media. Because ferrate ions have positive charge, negative charged media can shows the high phosphate removal efficiency.

$$
\begin{aligned}
& \equiv \mathrm{FeOH} \mathrm{O}^{\mathrm{O}}+\mathrm{PO}_{4}^{3-}+3 \mathrm{H}^{+} \leftrightarrow \equiv \mathrm{FeH}_{2} \mathrm{PO}_{4}+\mathrm{H}_{2} \mathrm{O} \\
& \equiv \mathrm{FeOH}{ }^{0}+\mathrm{PO}_{4}^{3-}+2 \mathrm{H}^{+} \leftrightarrow \equiv \mathrm{FeHPO}{ }_{4}^{-}+\mathrm{H}_{2} \mathrm{O}
\end{aligned}
$$

$$
\equiv \mathrm{FeOH}{ }^{0}+\mathrm{PO}_{4}^{3-}+\mathrm{H}^{+} \leftrightarrow \mathrm{FePO}_{4}^{2-}+\mathrm{H}_{2} \mathrm{O}
$$

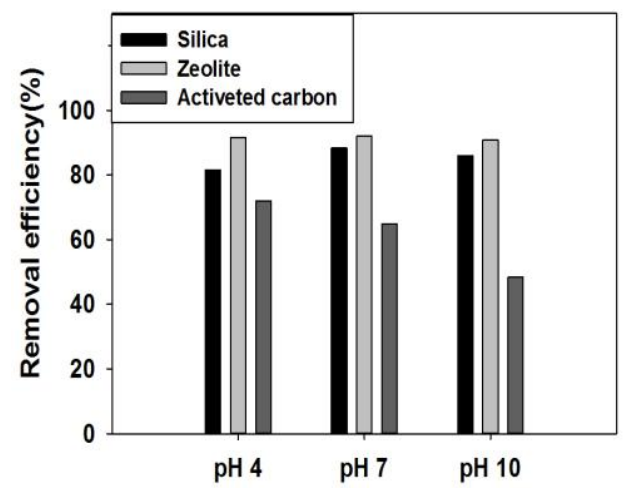

Fig. 3. The removal efficiency (\%) of phosphate with 20 min of treatment in the $\mathrm{pH}$ of 4,7 , and 10 .

Fig. 4 shows the removal efficiency of each media after 60 min of treatment. Silica and zeolite shows about $90 \%$ of removal efficiency of phosphate, and the activated carbon shows lowest removal efficiency. As the $\mathrm{pH}$ increased, the phosphate removal efficiency of activated carbon is decreased.

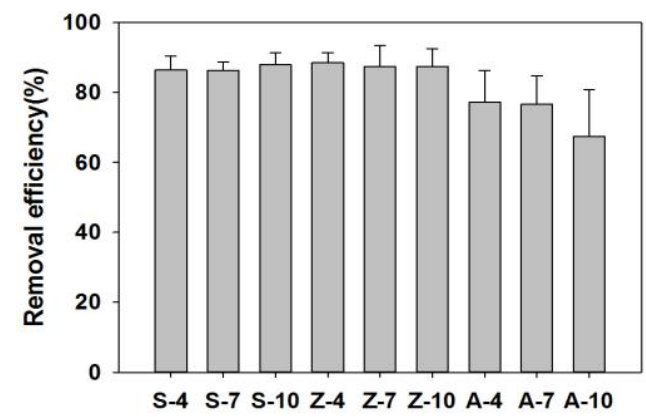

Fig. 4. The removal efficiency (\%) of phosphate after $60 \mathrm{~min}$ of treatment in

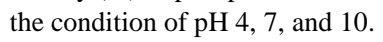

\section{CONCLUSION}

In this study, three kinds of media(zeolite, activated carbon, and quarts sands) is coated with hydrated ferric oxides(HFO) and the removal efficiency of phosphorus was investigated. The silica and zeolite shows high phosphate removal efficiency. It can be explained by zeta potential of each media.

\section{ACKNOWLEDGMENT}

This research is supported by Korea Ministry of Environment(MOE) as “ Global Top PROJECT (2016002210006)

\section{REFERENCES}

[1] E. N. Peleka, P. P. Mavros, D. Zamboulis, and K. A. Matis, "Removal of phosphates from water by a hybrid flotation-membrane filtration cell," Desal. vol. 198, pp. 198-207, 2005.

[2] Y. Seida and Y. Nakano, "Removal of phosphate by layered double hydroxides containing iron," Water Res. vol. 36, pp. 1306-1312, 2002.

[3] M. Razali, Y. Zhao, and M. Bruen, "Effectiveness of a drinking-water treatment sludge in removing different phosphorus species from aqueous solution," Sep. Purif. Technol. vol. 55, pp. 300-306, 2007. 
[4] R. Awual, "A. Jyo, Rapid column-mode removal of arsenate from water by crosslinked poly(allylamine) resin," Water Res. vol. 43, pp. 1229-1236, 2009.

[5] M. R. Awual, "A. jyo, assessing of phosphorus removal by polymeric anion exchangers," Desal. vol. 281, pp. 111-117, 2011.

[6] K. Kędziora, J. Piasek, J. Szerement, and J. Cieśla, "Modification of zeolite surface charge for wastewater treatment," presented at the BioPhys, Nitra, Slovakia, June 18, 2014.

[7] N. Y. Acelas, B. D. Martin, D. Lopez, and B. Jefferson, "Selective removal of phosphate from wastewater using hydrated metal oxide dispersed with in anionic exchange media," Chemo, 2015.

[8] E. M. Bennett and M. E. Schipanski, "The phosphorus cycle, fundamental of ecosystem science," Elsevier, 2013, pp. 246-294.

[9] R.W. Scholz, A. E. Ulrich, and M. Eilittä, and A. Roy, "Sustainable use of phosphorus: A finite resource," Sci. Total Environ., 2013, pp. $461-462$.

[10] S. Röhling, Globale Verfügbarkeit von Dünger- und Energierohstoffen, in: AHT Niederorschel Und Der Volksbank Dransfeld Proc., 2010.

[11] E. Oguz, "Thermodynamic and kinetic investigations of PO3-4 adsorption on blast furnace slag," J.Colloid Interface Sci., 2015.

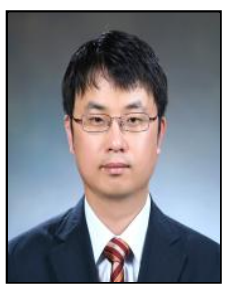

Chan-gyu Park is a senior researcher in environmental convergence technology center at Korea Testing Laboratory-KTL, Korea. He completed his Ph.D. in civil \& environment engineering department at Yonsei University, Korea in 2010. His research interests covers the water treatment system development \& standardization for water re-use. Currently, his group is researching on standardization of distillation \& AOP technology for water re-use 